\title{
Thermal and Economic Analysis of Gas Turbine Using Inlet Air Cooling System
}

Thamir K. Ibrahim ${ }^{1, ~}{ }^{*}$, Mohammed K. Mohammed ${ }^{2}$, Omar I. Awad ${ }^{1}$ Rizalman Mamat ${ }^{1}$ and Abdolbaqi M. $\mathrm{Kh}^{1}$

${ }^{1}$ Faculty of Mechanical Engineering, University Malaysia Pahang, 26600 Pekan, Pahang, Malaysia

${ }^{2}$ Mechanical Engineering Department, University of Sharjah, UAE,

\begin{abstract}
A basic goal of operation management is to successfully complete the life cycle of power systems, with optimum output against minimal input. This document intends calculating both, the performance and the life cycle cost of a gas turbine fitted with an inlet air cooling mechanism. Correspondingly, both a thermodynamic and an economic model are drawn up, to present options towards computing the cooling loads and the life cycle costs. The primary observations indicate that around $120 \mathrm{MWh}$ of power is derived from gas turbine power plants incorporating the cooling mechanism, compared to $96.6 \mathrm{MWh}$ for units without the mechanism, while the life cycle cost is lower for units incorporating the cooling process. This indicates benefits in having the mechanism incorporated in the architecture of a gas turbine.
\end{abstract}

\section{Introduction}

Considering an increased consciousness on the range of global warming challenges and the corresponding requirement for more cost efficient power production solutions, there are wide ranging studies on formulating new processes and systems to increase the output from gas turbine generators [1-3].

The gas turbine performance is functional to the ambient condition. As increase of the ambient air temperature arises, the compressor of the gas turbine can be compressed less air since the withdrawing capacity of compressor is given, and so the power output of the gas turbine is decrease at a given entry temperature of the turbine [4-6]. Additionally, the consumption work for the compression processes was increases because the volume of the air increases in proportionality to increase the ambient air temperature. Inlet air cooling system is important method for increase power output of gas turbine cycles.

Malewski and Holldorft [7], made studies on the effects of attaching an aqua-ammonia absorption chiller to gas turbines for cooling the inlet air, with a direct contact heat exchanger circulating the exhaust gases for the heat requirements. Subsequently, Johnson [8] recommended improving the efficiency levels in gas turbine generators by utilizing evaporative coolers. Ondryas and Haub [9] analyzed the utilization of vapour compression and aqua-ammonia absorption chillers to cool the inlet air, while DeLucia et al. [10]

* Corresponding author: thamir@ump.edu.my 
compared the impact on a cogeneration gas turbine power plant by doing away with the cooling system in its entirety. Jan [11] evaluated the impact of ambient temperatures affecting the operational indices of the gas turbines, concluding that a low inlet air temperature had an inverse effect on the flow rate of the combustion gases, ultimately contributing to power output increments. Erdem and Sevilgen [12] researched the effects on turbine performance incorporating an optional power booster, which included the placement of mechanized chillers adjacent to the thermal storage schematics. Valdes et al. [13] used a genetic algorithm to propose attaining the peak performance levels of a combined cycle gas turbine power plant. Accadia and Vanoli [14] researched the application of a structural method towards maximizing the operational output from a vapour compression heat pump. In all this, the inlet air is anticipated to boost the power output and the efficiency in gas turbines [15-19]. Considering the soaring cost of energy and the required investment, this is definitely of interest. This document emphasizes on an evaluation of the actions in gas turbine power plant systems since operational analysis goes towards providing ideal design parameters for gas turbine power plant systems under pre-arranged operating conditions. Attaching an inlet air cooler process to the gas turbine power plant requires a comprehensive analysis for inlet-air cooling technologies in ideal conditions. Above all, an in-depth economic perspective on the output of the complete cogeneration plant is also debated [20]. The conclusion summarizes that improved performance levels of the gas turbine inlet-air cooling mechanism translates to cash benefits and alternative economic incentives, all increasing the profit of the entire setup.

This research progresses systematically by elaborating across four different stages. In the first part, initially the performance of a single shaft gas turbine power plant is given a basic overview. Next to this, in the second stage, both the thermodynamic model and the corresponding economic model are drawn up and discussed. In the third stage, programming results are arrived upon keeping in perspective certain pre-conditions and limitations which are compared amongst themselves. In the fourth and the concluding stage, a few conclusions from the text are presented and summarized. Thus, the paper introduces the use of an absorption cooling system to improve the performance of the Gas Turbine of Baiji Power plant and analyses the life cycle cost for both case: gas turbine with and without air cooling system.

\section{Thermodynamic and Economic Modelling}

This text draws upon observations from our study of the Baiji gas turbine power station, installed with a Siemens V94.2 single shaft gas turbine power plant. Fig. 1, depicting the single shaft gas turbine generally utilized for electrical power generation, which is manufactured in a continuous shaft enabling all interlinked stages to operate at the uniform speed of 3000 RPMs. These types of units are typically used for electricity generation it was connected with absorption refrigeration cycle is show in Fig. 1.

\subsection{Thermodynamic and Economic Modelling}

Utilizing the first law of thermodynamics, and substituting the air inlet temperature to the compressor, pressure ratio $\left(r_{p}\right)$ and isentropic efficiency for compressor, the relationship for the compressor exit temperature is presented as [21-23]:

$$
\mathrm{T}_{2}=\mathrm{T}_{1}\left(1+\frac{\frac{\gamma_{a}-1}{\mathrm{r}_{\mathrm{p}}}-1}{\eta_{c}}\right)
$$


where $\eta_{c}$ and $r_{p}$ are the compressor efficiency and pressure ratios respectively, and the constants are $\gamma_{a}=1.4$ and $\gamma_{g}=1.33$.

Values for the compressor $\left(W_{c}\right)$ can be calculated as:

$$
W_{c}=\frac{c_{p a} T_{1}\left(\left(r_{p}^{\frac{\gamma_{a}-1}{\gamma_{a}}}-1\right) / \eta_{c}\right)}{\eta_{m}}
$$

where $\eta_{m}$ depicts the mechanical efficiency of the

compressor and $c_{p a}$ is the value for the specific heat of air, which can be calculated by Eq. (3) for a range of $200 \mathrm{~K}<\mathrm{T}<800 \mathrm{~K}$ [24-25].

$$
\begin{aligned}
& c_{p a}=1.0189 \times 10^{3}-0.13784 T_{a}+1.9843 \times 10^{-4} T_{a}^{2} \\
& +4.2399 \times 10^{-7} T_{a}^{3}-3.7632 \times 10^{-10} T_{a}^{4}
\end{aligned}
$$

where $T_{a}=\frac{T_{2}+T_{1}}{2}$ is in Kelvin.

Values for the specific heat of flue gas are calculated as [26]:

$$
\begin{aligned}
c_{p g}= & 1.8083-2.3127 \times 10^{-3} T+4.045 \times 10^{-6} T^{2} \\
& -1.7363 \times 10^{-9} T^{3}
\end{aligned}
$$

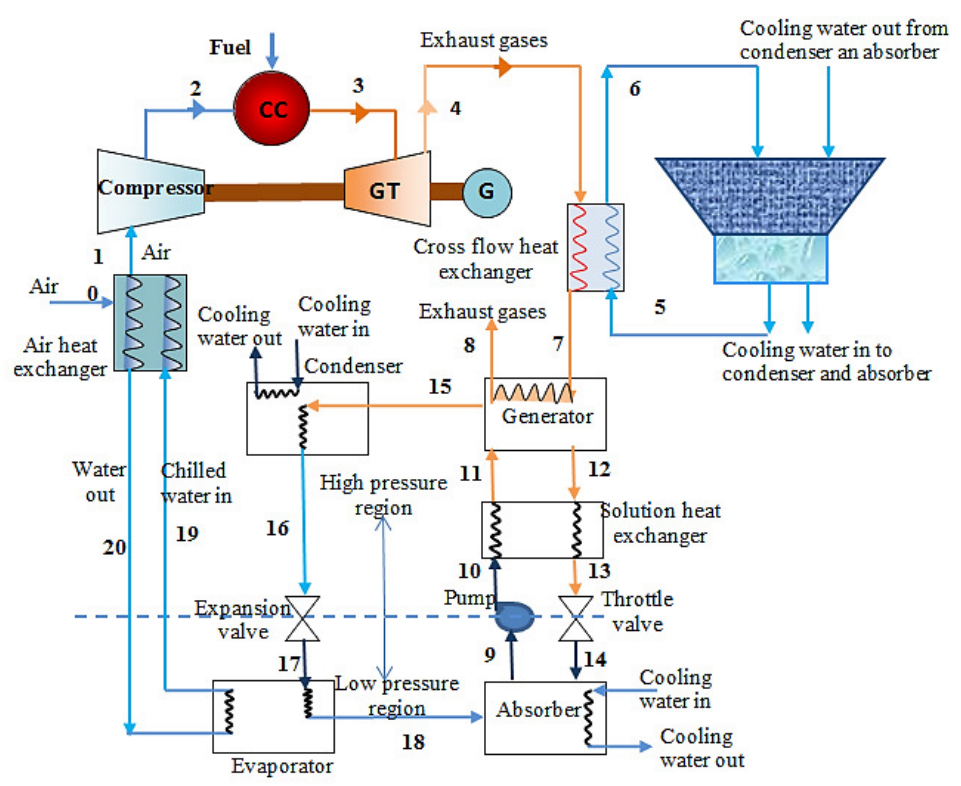

Fig. 1. Gas turbine with absorption cooling system. 
The energy balance in the combustion chamber is mathematically expressed as [6]:

$$
\dot{m}_{a} c_{p a} T_{2}+\dot{m}_{f} \times L H V+\dot{m}_{f} c_{p f} T_{f}=\left(\dot{m}_{a}+\dot{m}_{f}\right) \times c_{p g} T I T
$$

where, $\dot{m}_{f}$ is the fuel mass flow rate $(\mathrm{kg} / \mathrm{s}), \dot{m}_{a}$ is the air mass flow rate $(\mathrm{kg} / \mathrm{s}), L H V$ represents low heating value, $T_{3}=T I T=$ turbine inlet temperature, $C_{p f}$ is the specific heat of fuel, and $T_{f}$ is the temperature of the fuel [27].

The fuel air ratio $(f)$ is derived from equation 5 as [28]:

$$
f=\frac{\dot{m}_{f}}{\dot{m}_{a}}=\frac{c_{p g} \times T I T-c_{p a} T_{2}}{L H V-c_{p g} \times T I T}
$$

The heat supplied is expressed as:

$$
Q_{a d d}=c_{p g_{m}}\left(T I T-T_{1}\left(1+\frac{\frac{r_{p} \gamma^{\gamma_{a}}}{\gamma^{\prime}}-1}{\eta_{c}}\right)\right)
$$

The shaft work of the turbine is calculated as:

$$
W_{t}=c_{p g} T I T \cdot \eta_{t}\left(1-\frac{1}{r_{p}^{\frac{\gamma_{g}-1}{\gamma_{g}}}}\right)
$$

The total work performed by the gas turbine $\left(W_{\text {net }}\right)$ is calculated as:

$$
W_{n e t}=W_{t}-W_{c}
$$

The gas turbine efficiency is also calculated as:

$$
\eta_{t h}=\frac{W_{n e t}}{Q_{a d d}}
$$

The first law of thermodynamics is used towards calculating the cooling load of the refrigeration cycle, with the heat rejected from the cooling air given by Zhi-Gao, [29]:

$$
Q_{a i r}=\dot{m}_{a} c_{p a}\left(T_{a, \text { in }}-T_{a, \text { out }}\right)=Q_{e}
$$

where: $T_{a, \text { out }}=$ desired inlet air temperature, ideally $25^{\circ} \mathrm{C}$.

$T_{a, \text { in }}=$ air inlet mean temperature at summer condition being $45^{\circ} \mathrm{C}$

$Q_{e}=$ the heat transferred through the evaporator.

Coefficient of performance of the cooling system is given as: 


$$
C O P=\frac{Q_{e}}{Q_{g}+W_{p}}
$$

where: $Q_{g}=$ Heat transfer through generator

$W_{p}=$ work of the pump

\subsection{Economic model}

The life cycle cost $(L C C)$ is dependent on the actual power output generated by the gas turbine throughout the year, which can also be expressed as [20]:

$$
L C C_{n c}=\left\{\begin{array}{l}
I C_{g t}+E_{n c A n u} \times(P W F) \\
+M_{g t} \times(P W F)-S a l_{g t} \times(S P W)
\end{array}\right\}_{\text {original }}
$$

where

$\mathrm{LCC}_{\mathrm{nc}}$ : Life Cycle Cost without cooling

$\mathrm{IC}_{\mathrm{gt}}$ : Initial Cost of the gas turbine

$\mathrm{E}_{\mathrm{nc} \text { Anu: }}$ Annual Energy cost without cooling

$\mathrm{M}_{\mathrm{gt}}$ : Maintenance cost of the gas turbine

$\mathrm{Sal}_{\mathrm{gt}}$ : Salvage value of the gas turbine

PWF: Present Worth Factor

SPW: Single Present Worth

Eq. (13) can also be expressed as:

$$
\begin{aligned}
L C C_{n c}= & I C_{g t}+\sum_{1}^{12} \frac{P_{n c m} \times F_{p}}{\eta_{g t}} \times\left[\frac{1+f}{i-f}\left(1-\left(\frac{1+f}{1+i}\right)^{n}\right)\right] \\
& +M_{g t} \times\left[\frac{1+f}{i-f}\left(1-\left(\frac{1+f}{1+i}\right)^{n}\right)\right]-S_{g l} \times\left(\frac{1+f}{1+i}\right)^{n}
\end{aligned}
$$

where

Fp: Fuel price

Pncm: monthly power output without cooling

$\mathrm{f}$ : inflation rate

i: interest rate

$\mathrm{n}$ : period of investment

The single stage $\mathrm{LiBr}$ absorption system is utilized to increase the power output close to the extent permissible by the design of the unit, by cooling the inlet air to $15^{\circ} \mathrm{C}$ which ensures that the gas turbine operates as per the ISO design parameters [3]. Hence the life cycle cost of the combined system can be expressed as [14, 20,30]:

$$
\begin{aligned}
L C C_{w c}= & {\left[\begin{array}{l}
I C_{g t}+E_{w c A n u} \times(P W F)+M_{g t} \times(P W F) \\
-S a l_{g t} \times(S P W)
\end{array}\right]_{\text {original }} } \\
& +\left[\begin{array}{l}
I C_{a b s}-P_{a d p} \times(P W F)+M_{a b s} \times(P W F) \\
-S a l_{a b s} \times(S P W)
\end{array}\right]_{a b s o r p t i o n}
\end{aligned}
$$


The above may also be expressed as [17]:

$$
\begin{aligned}
& L C C_{w c}=\left[\begin{array}{l}
I C_{g t}+\sum_{1}^{12} \frac{P_{w c m} \times F_{p}}{\eta_{g t}} \times P W F \\
+M_{g t} \times P W F-S a l_{g t} \times\left(\frac{1+f}{1+i}\right)^{n}
\end{array}\right]_{\text {original }} \\
& +\left[\begin{array}{l}
I C_{a b s}-\frac{P_{a d t} \times F_{p}}{\eta_{g t}} \times P W F \\
+M_{a b s} \times P W F-S a l_{a b s} \times\left(\frac{1+f}{1+i}\right)^{m}
\end{array}\right]_{a b s o r p t i o n}
\end{aligned}
$$

\section{Results and discussion}

To increase the net power output of the gas turbine power plant, the inlet air temperature is reduced and brought down before it enters the compressor by the presence of an absorption cooling system utilizing single stage LiBr-water. The heat energy emitted from the exhaust gases of the power plant is utilized and made use of for continuously running the cooling system. By design and default, gas turbines are uniform volume units, and at a set shaft speed would continue circulating an equal volume of air. However, the turbine's power output significantly and greatly depends on the air-flowing through it. This would go on to explain how power output usually decreases on warm summer days, since the air is less dense due to the heat. A $1^{\circ} \mathrm{C}$ temperature increase in the inlet air, reduces the power output by $1 \%$, with the heat rate of the turbine also going up, all of which is a challenge for power engineers and technicians. A MATLAB software simulation code was presented for depicting a life cycle, towards investigating the consequences of utilizing the inlet air and observing the power generation and economic outputs of the power plant. Fig. 2 shows the comparison between the simulated power outputs and the real results obtained from Baiji GT power plant. As compared to the real data from Baiji GT power plant, the simulated output power is higher. This is because of an incomplete combustion caused by the usage of fuel oil instead of natural gas in the Baiji plant. An overall reduction in the efficiency was felt (Graus and Worrel, 2009). Fig. 3 exhibits that an average daily output of 2875 MWh was obtained in January, both with and without utilizing cooling techniques. The low ambient temperatures running throughout January contributed to the setup generating power almost equal to the maximum specified limits. Fig. 3 also depicts a high output in power production during the mornings (up to $121 \mathrm{MW} / \mathrm{h}$ ), which then gradually tapers off to $118 \mathrm{MW} / \mathrm{h}$ by midday due to increase in the afternoon temperatures, followed by output again increasing as the daytime temperatures cool off. 


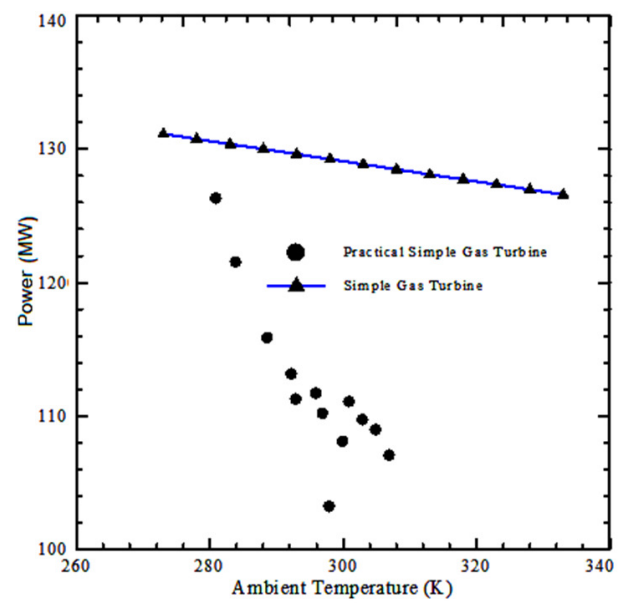

Fig. 2. Comparison between simulated power outputs versus real results from Baiji gas turbine power plant.

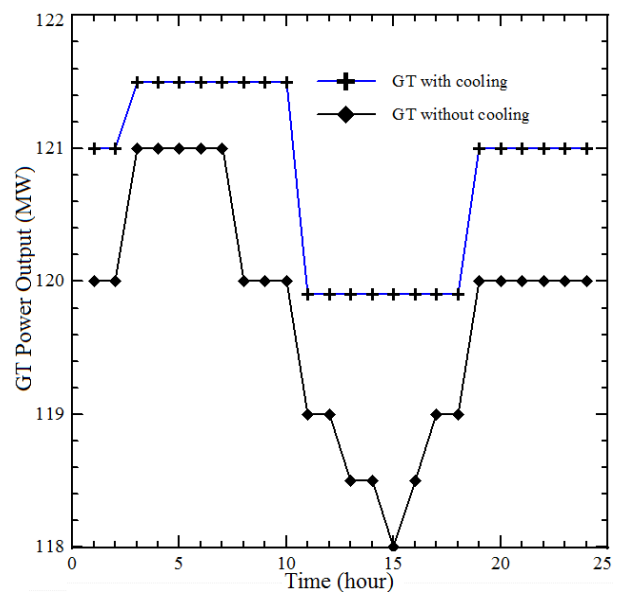

Fig. 3. GT net power output with and without cooling system for January.

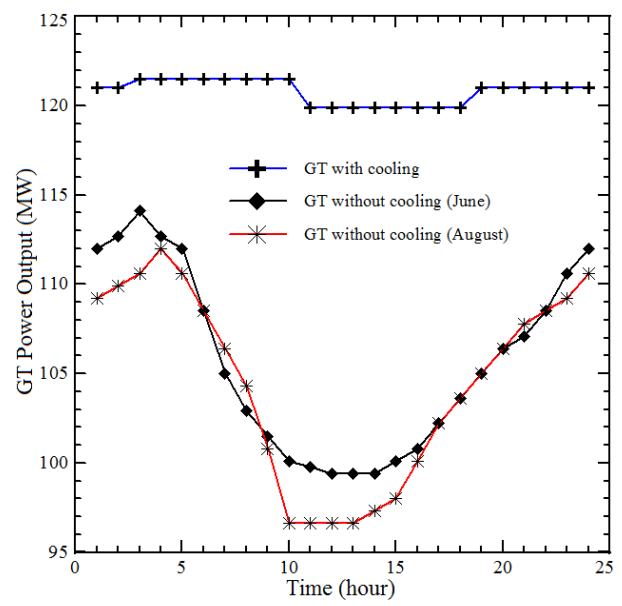

Fig. 4. Gas turbine net power output with and without cooling system for the month of June and August. 
Overall power production and output was observed to fall during the Iraqi summers of May to October. Fig. 4 exhibits the power production in June and August observed on an hourly basis from the gas turbines. The graphical representation shows for the production figures in both scenarios where cooling was, and was not employed. Fig. 4 exhibits an average net power output of $2535.75 \mathrm{MWh}$ while the turbines were running without the inlet air being cooled, which was an average $11.9 \%$ decrease in daily power output, while the maximum decrease per day is observed at $17.2 \%$. The major variations in these figures can be attributed to the temperature extremes observed in Baiji City, where day time temperatures soar, and night time temperatures fall considerably over a 24 hour period in June. As well as Fig. 4 exhibits readings for daily power output in August from the turbines, with and without the cooling system deployed. Output was calculated at 2507.4 MWh, which correspondingly goes to show an overall $12.7 \%$ decrease in power output, against the manufacturer's maximum and optimum designation of $2871 \mathrm{MWh}$. It is also to be noted that the highest reduction observed stood at $19.5 \%$ for the 24 hour period. Normally, the hot summer months of June, July and August are amongst the warmest periods of the year, with temperatures often hovering at $45^{\circ} \mathrm{C}$. Considering and accounting for this, it is important that the cooling system be employed at all times so that power generation is optimized and maximized to the extent possible.

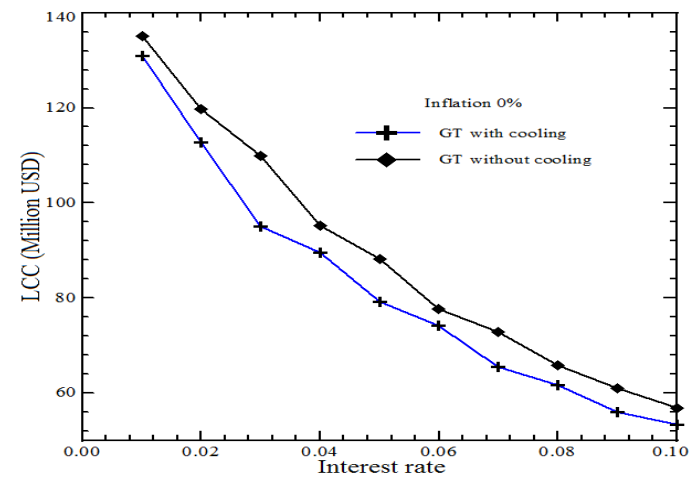

(a) inflation rate $0 \%$

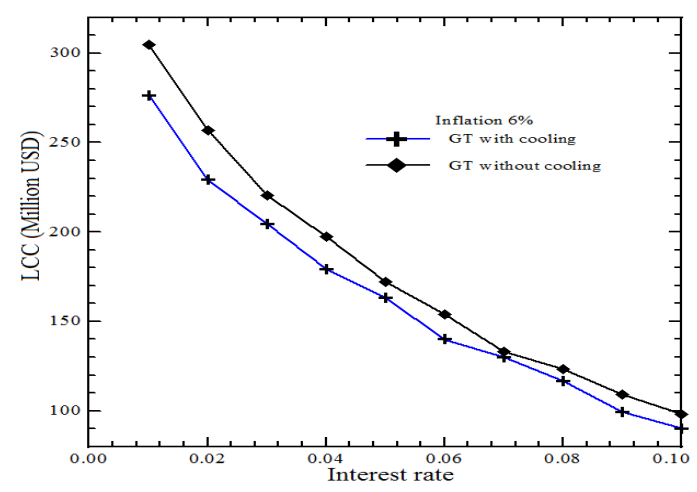

(b) inflation rate $6 \%$

Fig. 5. Life cycle costs for gas turbine power plant with and without cooling system for various interest rates. 
Both, a gas turbine power plant and the single stage absorption system are calculated to have a production life of around 30 years. Interest rates for financing are normally in the range of $0 \%$ to $10 \%$, accounting for an annual inflation rate of between $0 \%$ and $6 \%$. For this study, we have considered running the turbines with and without a cooling mechanism in place, and the corresponding annual cost incurred in running the turbines with and without a cooling mechanism is also considered towards calculating the life cycle cost. The values observed under both scenarios are held up to observation. Hence, fig. 5 is a representation of the life cycle costs for the operation of the turbine, with and without the cooling mechanism installed, while accounting for an inflation rate of between $0 \%$ and 6\%. Fig. 5(a) depicts that the life cycle cost of the entire mechanism is lower by almost $4 \%$, when the cooling unit is a part of the architecture, while accounting for corresponding inflation being $0 \%$ over the 30 year period of the turbine's life. Fig. 5(b) exhibits a $12 \%$ savings when the inflation is at $6 \%$, and the interest rate is at $0.01 \%$. In numerical terms, this would translate to lifetime costs of $135.6 \mathrm{M} \$$ and $302 \mathrm{M} \$$ at 0.01 interest rates. To conclude, accounting for a standardized interest rate at $0.01 \%$, a savings of $3.8 \mathrm{M} \$$ is projected at $0 \%$ inflation, and a $26 \mathrm{M} \$$ savings is projected when annual inflation is calculated at $6 \%$.

\section{Conclusion}

The document has presented a comparison on the life cycle cost incurred on the gas turbine power plant, by both utilizing and deferring the use of an inlet air cooling mechanism. Factors taken into consideration include issues of capital investment, maintenance costs, and the energy costs incurred during the lifetime of the power plant. However, a constraint in the study is the limitations in correctly calculating the life cycle costs since a whole range of overheads cannot be accurately accounted for as manufacturers of the machinery are reluctant to disclose such data and figures. The findings of the current study are summarized as:

1. A decrease in inlet air temperature of the compressor of the GT, keeping the other parameter Constant led to decrease the LCC.

2. The LCC for the GT power plant with absorption refrigeration case is lower than that of using GT power plant by $3.9 \%$.

3. The economic analysis indicated that applying a single stage $\mathrm{LiBr}$ to augment the GT power output in hot day is a valuable technique and should be considered.

The authors would like to thank Universiti Malaysia Pahang for provides laboratory facilities and financial support under research grant (RDU 150334).

\section{References}

1. T. K. Ibrahim, M. Rahman and A. N. Abdalla, Int. J. Phys. Sci., 6 (4), 620-627 (2011).

2. M. M. Rahman, T. K. Ibrahim, K. Kadirgama, R. Mamat and R. A. Bakar, presented at the Adv. Mat. Res., (2011) (unpublished).

3. T. K. Ibrahim, M. Rahman and K. Sharma, presented at the International Conference on Mechanical and Electrical Technology, 3rd,(ICMET-China 2011), Volumes 1-3, (2011) (unpublished).

4. M. Rahman, T. K. Ibrahim, M. Taib, M. Noor, K. Kadirgama and R. A. Bakar, Fuel 200 (4), 2 (2010).

5. M. Rahman, T. K. Ibrahim and A. N. Abdalla, Int. J. Phys. Sci., 6 (14), 3539-3550 (2011).

6. T. K. Ibrahim and M. N. Mohammed, Int. J. Energ. Sci. Eng., 1 (2), 10 (2015). 
7. W. F. Malewski and G. M. Holldorff, presented at the ASME 1986 International Gas Turbine Conference and Exhibit, (1986) (unpublished).

8. R. Johnson, J. Eng. Gas Turb. Power., 111 (2), 327-334 (1989).

9. I. S. Ondryas, D. A. Wilson, M. Kawamoto and G. L. Haub, J. Eng. Gas Turb. Power., 113 (2), 203-211 (1991).

10. M. De Lucia, R. Bronconi and E. Carnevale, presented at the ASME 1993 International Gas Turbine and Aeroengine Congress and Exposition, (1993) (unpublished).

11. J. Szargut, Int. J. Energ. Res., 24 (9), 821-830 (2000).

12. H. H. Erdem and S. H. Sevilgen, Appl. Therm. Eng., 26 (2), 320-326 (2006).

13. M. Valdés, M. D. Duran and A. Rovira, Appl. Therm. Eng., 23 (17), 2169-2182 (2003).

14. M. D. d'Accadia and L. Vanoli, Int. J. Refrig., 27 (4), 433-441 (2004).

15. T. K. Ibrahim and M. Rahman, Adv. Mech. Eng., 6, 781503 (2014).

16. T. K. Ibrahim and M. Rahman, J. Mech. Eng. Sci. (JMES), 4, 14 (2013).

17. T. K. Ibrahim and M. Rahman, Int. J. Automot. Mech. Eng., 12 (2015).

18. T. K. Ibrahim, M. Rahman and A. N. Abdalla, Procedia Engineer., 15, 4216-4223 (2011).

19. T. K. Ibrahim and M. Rahman, Int. J. Automot. Mech. Eng., 9, 1747 (2014).

20. T. K. Ibrahim, Tikrit J. Eng. Sci. (TJES), 22 (1), 69-75 (2015).

21. F. Basrawi, T. K. Ibrahim, K. Habib and T. Yamada, Energy, 97, 262-272 (2016).

22. F. Basrawi, T. K. Ibrahim, G. C. Lee, K. Habib and H. Ibrahim, J. Sol. Energ., 137 (6), 061009 (2015).

23. T. K. Ibrahim, M. Rahman, O. M. Ali, F. Basrawi and R. Mamat, presented at the MATEC Web of Conferences, 2016 (unpublished).

24. F. Basrawi, M. Chand, K. Koo and T. K. Ibrahim, presented at the MATEC Web of Conferences, 2016 (unpublished).

25. T. K. Ibrahim, M. Rahman and A. N. A. Alla, Sci. Res. Essays., 5 (23), 3760-3770 (2010).

26. T. K. Ibrahim and M. Rahman, J. Energ. Resour. Technol., 137 (6), 061601 (2015).

27. T. K. Ibrahim, M. Rahman, M. Mohammed and F. Basrawi, Int. J. Automot. Mech. Eng. (IJAME), 13 (1), 11 (2016).

28. W. Han, Q. Chen, R.-m. Lin and H.-g. Jin, Applied Energy 138, 160-168 (2015).

29. Z.-G. Sun, Energ. Buildings, 40 (2), 126-130 (2008).

30. O. Balli, H. Aras and A. Hepbasli, Energ. Convers. Manage., 51 (11), 2260-2271 (2010). 